\title{
An exploration study to detect important factors influencing insurance firms
}

\author{
Farzaneh Soleimani $^{\mathrm{a}^{*}}$, Fattaneh Alizadeh Meshkani $^{\mathrm{b}}$ and Abdullah Naami ${ }^{\mathrm{b}}$
}

${ }^{a}$ M.A. in Marketing, Islamic Azad University, South Branch, Tehran, Iran

${ }^{b}$ Assistant Professor, Department of Management, Islamic Azad University, South Tehran Branch, Tehran, Iran

C H R O N I C L E

Article history:

Received May 12, 2013

Received in revised format

12 August 2013

Accepted 28 September 2013

Available online

October 82013

Keywords:

Insurance firm

Competition

Marketing planning

\section{A B S T R A C T}

\begin{abstract}
The recent trend on competition among insurance firms has increased motivation to look for important factors influencing this industry. In this paper, we present an empirical investigation to find important factors shaping this industry. The proposed study designs a questionnaire in Likert scale and, using principal component analysis, detects important factors on the success of this industry. Cronbach alpha is calculated as 0.849, and Kaiser-Meyer-Olkin and Bartlett's Test are calculated as 0.873 and 12744 with (Sig. $=0.000$ ), respectively. The study has detected four important factors including quality of service casualties, sales improvement and advertisement, quality of issuance of insurance policies and quality of work force.
\end{abstract}

(C) 2013 Growing Science Ltd. All rights reserved.

\section{Introduction}

Measuring the relative performance of insurance companies plays an essential role on making strategic decisions in this industry (Aaker, 2010; Klumpes, 2004). There are many techniques applied for measuring the relative performance of insurance companies and for detecting important factors influencing each insurance unit. Some of these techniques are involved with multi criteria decision making techniques, which help us rank various alternatives. Analytical hierarchy process, for instance, is one of the most popular methods, which has widely been implemented by many people (Saaty, 1977, 1988). Nevertheless, many factors on insurance industry depend on uncertainty and people may look for various methods such as fuzzy logic to handle uncertainty (Shapiro, 2004). The insurance industry has different areas with potential applications for fuzzy logic (FL). These include different issues such as classification, underwriting, projected liabilities, fuzzy future and present values, etc.

*Corresponding author. Tel: +989126873685

E-mail address: f.soleimani984@yahoo.com (Farzaneh Soleimani)

(C) 2013 Growing Science Ltd. All rights reserved. doi: $10.5267 / j . m s 1.2013 .10 .011$ 
Yücenur and Demirel (2012), in an assignment, offered a group decision making process for insurance company selection problem with extended VIKOR technique under fuzzy environment. Sayadi et al. (2009) applied extension of VIKOR method for decision making problem with interval numbers. Korhonen and Voutilainen (2006) presented some important results on the most preferred alliance structure between banks and insurance firms. Phillips et al. (1998) presented a technique for financial pricing of insurance in the multiple-line insurance company. Taksar (2000) presented optimal risk and dividend distribution control techniques for an insurance company. Azizi et al. (2013) presented an AHP method for identifying influential factors on insurance cost. Tabatabaei et al. (2013) presented an application of Fuzzy DEMATEL electronic life-insurance development.

\section{The proposed study}

We present an empirical investigation to find important factors shaping this industry. The proposed study designs a questionnaire in Likert scale and, using principal component analysis, detects important factors on the success of this industry. Cronbach alpha has been calculated as 0.849 , and Kaiser-Meyer-Olkin and Bartlett's Test are calculated as 0.873 and 12744 with (Sig. $=0.000$ ), respectively. The sample size is calculated as follows,

$N=Z_{\alpha / 2}^{2} \frac{p \times q}{e^{2}}$,

where $N$ is the sample size, $p=1-q$ represents the probability, $z_{\alpha / 2}$ is CDF of normal distribution and finally $\varepsilon$ is the error term. For our study, we assume $p=0.5, z_{\alpha / 2}=1.96$ and $e=0.05$, the number of sample size is calculated as $N=384$. The proposed study distributed 400 questionnaires and managed to collect 384 filled ones. The questionnaires were distributed among regular customers of one of Iranian insurance firm named Asia. All 40 questions of the survey were arranged in Likert scale in five spectrums including completely disagree $(-2)$, disagree $(-1)$, nutral, agree $(+1)$ and completely agree (+2). Fig. 1 demonstrates the results of Scree plot.

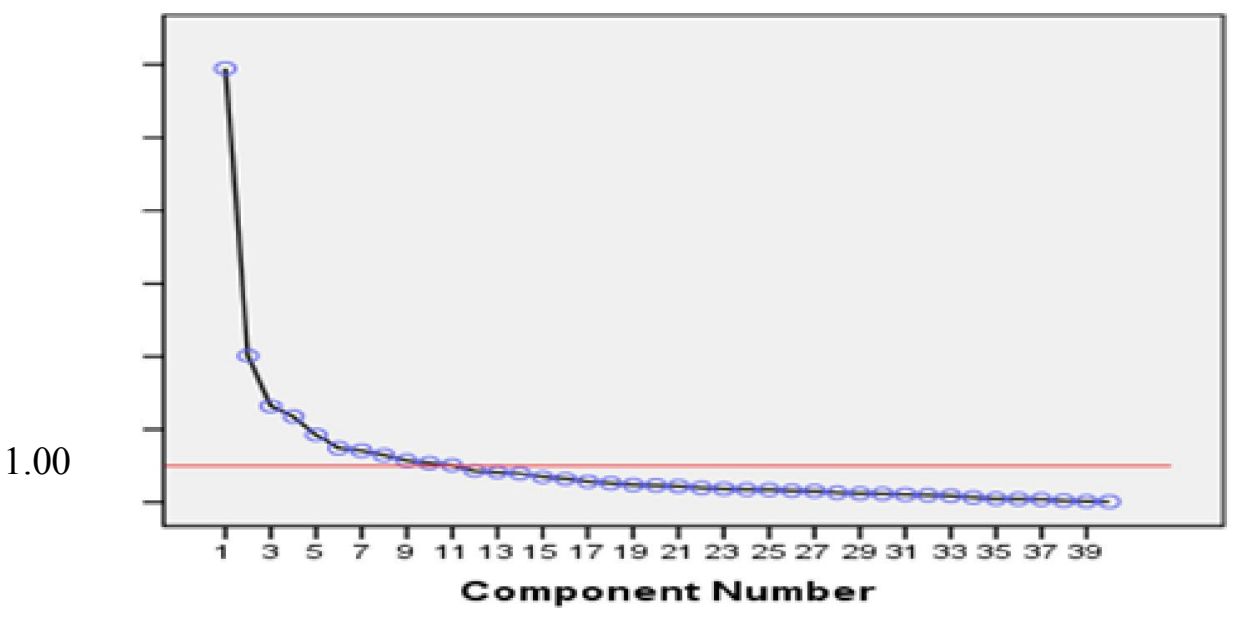

Fig. 1. The summary of Scree plot

As we can observe from the results of Fig. 1, there are eleven factors, which could be extracted for further studies. In addition, we have calculated a weighted factor for each component of eleven factors and by drawing a factor versus another one, we provide some insights about the status of insurance firm of an Iranian insurance firmed named ASIA. 


\section{The results}

In this section, we present details of our findings on eleven influencing factors. We first present details of each eleven factors.

\subsection{The results of principal component analysis}

\subsubsection{The first factor: Quality of service casualties}

The first factor is associated with quality of service casualties with seven factors, which are summarized on Table 1. As we can observe from the results of Table 3, fair amount of paid compensation, ensuring the accuracy of calculation and damage evaluation, fast and reliable damage assessment process and quality of services in the event of damage are among the most important items. In addition, providing information to customers on how to evaluate and calculate the amount of damage, suitable equipment for serving customers and access to advanced equipment are also other secondary important issues. Let $W$ and $\bar{X}$ be the factor weight and average score calculated from questionnaires in Likert spectrum, respectively. Therefore, we can calculate the average weight for each eleven factors. For the case of quality of service casualties, we have $\sum_{i=1}^{7} w_{i} \cdot \bar{x}_{i k}=-0.22621$.

Table 1

The summary of factors associated with quality of service casualties

\begin{tabular}{lcc}
\hline Option & $W$ & $\bar{X}$ \\
\hline Fair amount of paid compensation & .932 & 0.107895 \\
\hline Ensuring the accuracy of calculation and damage evaluation & .928 & 0.107895 \\
Fast and reliable damage assessment process & .926 & 0.126316 \\
Quality of services in the event of damage & .920 & 0.136840 \\
Providing information to customers on how to evaluate and calculate the amount of damage & .795 & -0.186840 \\
Suitable equipment for serving customers & .519 & -0.489470 \\
Access to advanced equipment & .518 & -0.515790 \\
\hline
\end{tabular}

\subsubsection{The second factor: Sales improvement and advertisement}

Sales improvement and advertisement is the second important factor and it includes five factors, which are summarized in Table 2 as follows,

Table 2

The summary of factors associated with sales improvement and advertisement

\begin{tabular}{lcc}
\hline Option & $W$ & $\bar{X}$ \\
\hline Quality and quantity of advertisement & .878 & -0.55526 \\
The effect of advertisement & .846 & -0.57895 \\
Diversity of services & .785 & -0.52632 \\
Clarity and completeness of the advertisement & .738 & -0.54737 \\
Providing electronic services to customers & .531 & -0.34421 \\
\hline
\end{tabular}

According to the results of Table 2, quality and quantity of advertisement is the most important item followed by the effect of advertisement, diversity of services, clarity and completeness of the advertisement and providing electronic services to customers. The average weight is calculated as $\sum_{i=1}^{7} w_{i} \bar{x}_{i k}=-1.99844$ 


\subsubsection{The third factor: Quality of insurance services}

Quality of insurance services is another important factor with three items summarized in Table 3.

Table 3

The summary of factors associated with quality of insurance services

\begin{tabular}{llc}
\hline \multicolumn{1}{c}{ Option } & $W$ & $\bar{X}$ \\
\hline Ease of rate inquiry & .776 & 0.126316 \\
\hline Fast and reliable issuance of insurance policy & .706 & 0.107895 \\
Providing necessary information about the risks insured & .677 & 0.107895 \\
\hline Providing information about insurance discounts & .599 & 0.136840 \\
Providing information on how to calculate premium rates and payments & .431 & -0.18684 \\
\hline The amount of word of mouth advertisement & .427 & -0.48947 \\
\hline
\end{tabular}

According to the results of Table 3, ease of rate inquiry, fast and reliable issuance of insurance policy and providing necessary information about the risks insured. The average weight is calculated as $\sum_{i=1}^{7} w_{i} \bar{x}_{i k}=0.289187$.

\subsubsection{The fourth factor: Quality of workers}

Quality of workers is another important factor with four items summarized in Table 4. According to the results of Table 4, observing courtesy and respect by the staff and company representatives, adornment and covered employees and company representatives and management experts in the event of damage. The average weight is calculated as $\sum_{i=1}^{7} w_{i} \bar{x}_{i k}=2.3345$.

Table 4

The summary of factors associated with quality of workers

\begin{tabular}{lcc}
\hline Option & $W$ & $\bar{X}$ \\
\hline Observing courtesy and respect by the staff and company representatives & .866 & 0.810526 \\
\hline Adornment and covered employees and company representatives & .819 & 0.673684 \\
Management experts in the event of damage & .816 & 0.815789 \\
Flexibility to request changes in insurance coverage & .714 & 0.581579 \\
\hline
\end{tabular}

\subsubsection{The fifth factor: Quality of distribution channels}

Quality of distribution channels is another important factor with three items summarized in Table 5. According to the results of Table 5, availability of knowledge and information is the most important factor followed by consulting services by experts and company representatives, easy access to branches and agencies insurance policy issued.

Table 5

The summary of factors associated with quality of distribution channels

Option

Availability of knowledge and information

Factor weight

Consulting services by experts and company representatives .863

Easy access to branches and agencies insurance policy issued .816

Easy access to branches or agencies in the event of damage 


\subsubsection{The sixth factor: Pricing strategy}

Pricing strategy the next important factors with three items summarized in Table 6 . According to the results of Table 6, fair amount of premiums is the most important item followed by compliance of the terms of insurance with company advertisements.

\section{Table 6}

The summary of factors associated with pricing strategy

\begin{tabular}{lc}
\hline \multicolumn{1}{c}{ Option } & Factor weight \\
\hline Fair amount of premiums & .730 \\
Compliance of the terms of insurance with company advertisements & .702 \\
Availability of a variety of insurance & .624 \\
\hline
\end{tabular}

\subsubsection{The seventh factor: Flexibility and diversity of services}

Flexibility and diversity of services is the next important factors with three items summarized in Table 7. According to the results of Table 7, good fitness between customers' needs and insurance premiums is the most important item.

\section{Table 7}

The summary of factors associated with pricing strategy

\begin{tabular}{lc}
\hline \multicolumn{1}{c}{ Option } & Factor weight \\
\hline Good fitness between customers' needs and insurance premiums & .708 \\
Having the opportunity to access managers in the case of emergency & .578 \\
Variety of payment of premium & .522 \\
\hline
\end{tabular}

\subsubsection{The eighth factor: Reducing the administrative bureaucracy}

Reducing the administrative bureaucracy is the next important factors with two items summarized in Table 8 where insured portion of the franchise is the most important item.

\section{Table 8}

The summary of factors associated with reducing the administrative bureaucracy

\begin{tabular}{lc}
\multicolumn{1}{c}{ Option } & Factor weight \\
\hline Insured portion of the franchise & .822 \\
Documents reasonably requested to avoid excessive bureaucracy & .789 \\
\hline
\end{tabular}

\subsubsection{The ninth factor: Quality of resolving complains}

Quality of resolving complains is the next important factors with two items summarized in Table 9 where creating a fair and quick opportunity for resolving conflicts is the most important item.

Table 9

The summary of factors associated with quality of resolving complains

\begin{tabular}{lc}
\hline \multicolumn{1}{c}{ Option } & Factor weight \\
\hline Creating a fair and quick opportunity for resolving conflicts & .857 \\
Having suitable opportunity for resolve the conflicts & .833 \\
\hline
\end{tabular}




\subsubsection{The tenth factor: Keeping customers inform about events}

Keeping customers inform about events is the next important factors with two items summarized in Table 10 where informing customers about the expiry dates of insurances is the most important item.

\section{Table 10}

The summary of factors associated with keeping customers inform about events

\begin{tabular}{lc}
\hline \multicolumn{1}{c}{ Option } & Factor weight \\
\hline Keeping customers inform about the expiry dates of insurances & .704 \\
Keeping in touch with customers during the time of insurance programs & .689 \\
\hline
\end{tabular}

\subsubsection{The eleventh factor: Company background and history}

Company background and history is the last important factors with two items summarized in Table 11 where facilities and financial prosperity is the most important item.

\section{Table 11}

The summary of factors associated with company background and history

\begin{tabular}{|c|c|}
\hline Option & Factor weight \\
\hline Facilities and financial prosperity & .882 \\
\hline Company experience & .758 \\
\hline
\end{tabular}

\subsection{The results of comparing different factors}

In this section, we compare the information of the first four factors using the weighted numbers calculated for each factor. Fig. 2 shows details of the advertisement versus quality of service casualties and quality of workers.

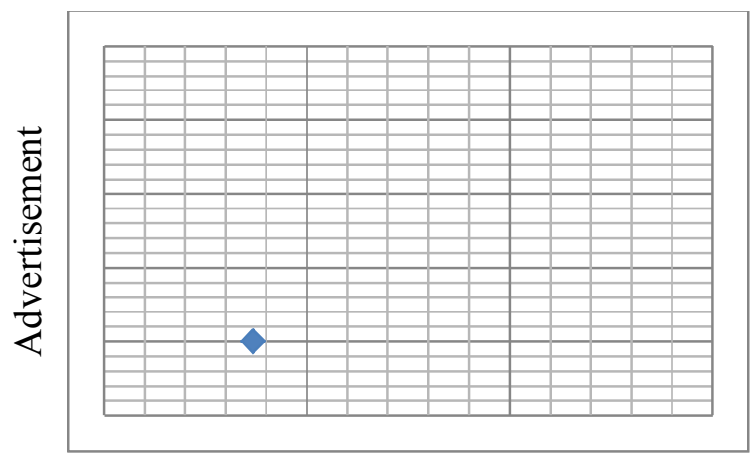

Quality of service casualties

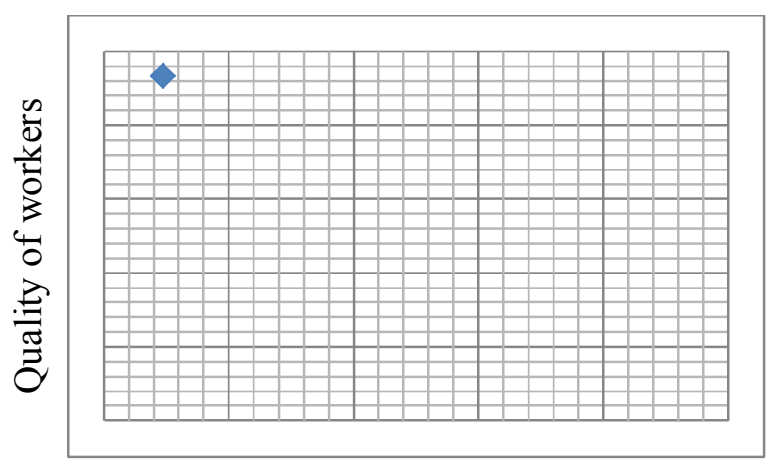

Quality of service casualties

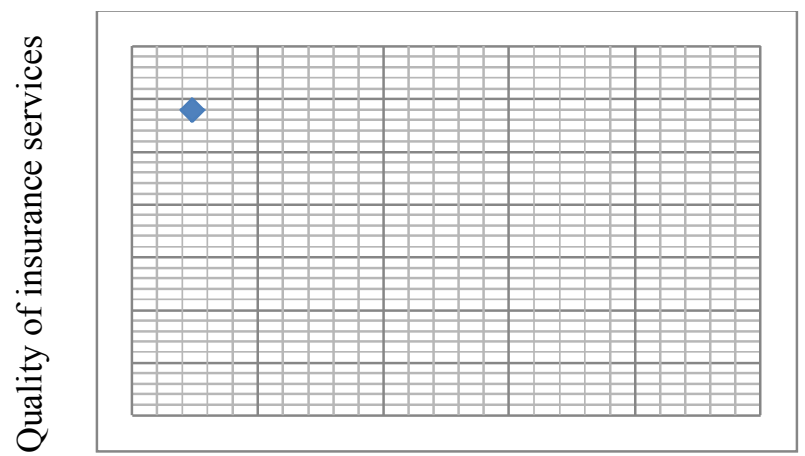

Quality of service casualties

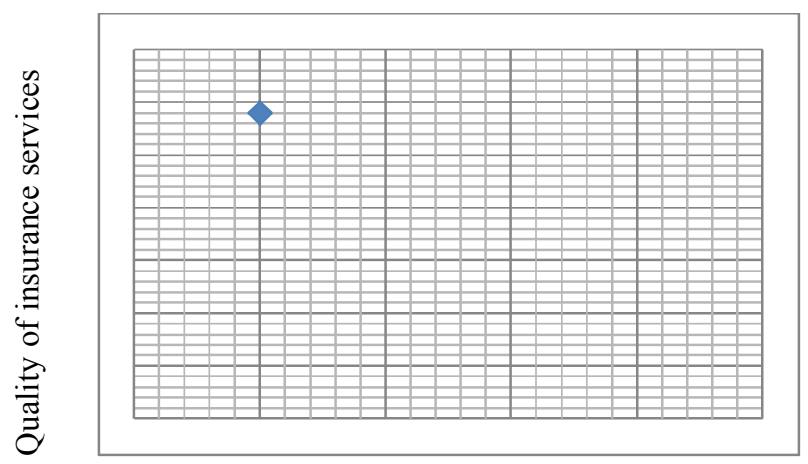

Advertisement 

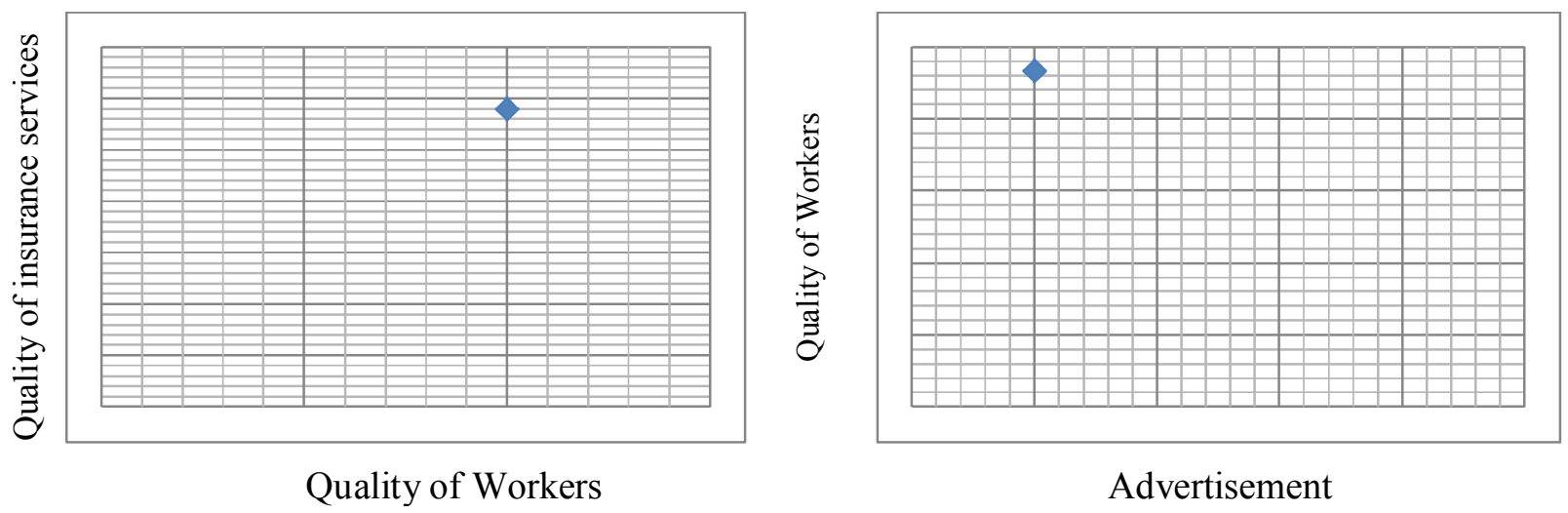

Fig. 2. The position of the firm based on selected factors

As we can observe from the results of Fig. 2, advertisement along with quality of service casualties are both in poor position and the management of must improve these items. While the qualities of insurance services are relatively in good position, the quality of service casualties seems to be relatively poor. While the quality of workers is relatively high, the quality of service casualties is relatively poor and finally, quality of insurance services is better positioned compared with sales and advertisement. Finally, it seems that quality of workers versus quality of insurance services are in good quality.

\section{Conclusion}

Insurance companies play essential role on people's daily activities such as having a car accident, visiting a physician, etc. When people receive good service from insurance companies, they may wish to convey a good message to others through the word of mouth advertisement, etc. This paper has presented an empirical investigation to find important factors influencing an insurance firm in Iran. The proposed study has detected eleven factors and based on the first four important factors including quality of service casualties, sales improvement and advertisement, quality of insurance services and quality of workers, we have investigated the present status of this insurance firm compared with other firms. The survey has indicated that advertisement along with quality of service casualties are both in poor position and the management of must improve these items. While the qualities of insurance services are relatively in good position, the quality of service casualties seems to be relatively poor. While the quality of workers is relatively high, the quality of service casualties is relatively poor and finally, quality of insurance services is better positioned compared with sales and advertisement.

\section{Acknowledgment}

The authors would like to thank the anonymous referees for their construction comments on earlier version of this work.

\section{References}

Aaker, J.L. (2010). Dimensions of brand image. Journal of Marketing Research, 34(3), 347-57.

Azizi, F., Jafarzadeh Kenari, M., \& Nasiri, M. (2013). An AHP method for identifying influential factors on insurance cost. Management Science Letters, 3(9), 2479-2482.

Klumpes, P. J. (2004). Performance benchmarking in financial services: Evidence from the UK life insurance industry. The Journal of Business, 77(2), 257-273.

Korhonen, P., \& Voutilainen, R. (2006). Finding the most preferred alliance structure between banks and insurance companies. European Journal of Operational Research, 175(2), 1285-1299. 
Phillips, R. D., Cummins, J. D., \& Allen, F. (1998). Financial pricing of insurance in the multiple-line insurance company. Journal of Risk and Insurance, 597-636.

Saaty, T. L. (1977). A scaling method for priorities in hierarchical structures.Journal of mathematical psychology, 15(3), 234-281.

Saaty, T. L. (1988). What is the analytic hierarchy process? (pp. 109-121). Springer Berlin Heidelberg.

Sayadi, M. K., Heydari, M., \& Shahanaghi, K. (2009). Extension of VIKOR method for decision making problem with interval numbers. Applied Mathematical Modelling, 33(5), 2257-2262.

Shapiro, A. F. (2004). Fuzzy logic in insurance. Insurance: Mathematics and Economics, 35(2), 399424.

Tabatabaei, S.V., Shahhosseini, M., Mozaffari, A., \& Taherdoost, Z. (2013). An application of Fuzzy DEMATEL electronic life-insurance development. Management Science Letters, 3(2), 491-498.

Taksar, M. I. (2000). Optimal risk and dividend distribution control models for an insurance company. Mathematical methods of operations research, 51(1), 1-42.

Yücenur, G. N., \& Demirel, N. Ç. (2012). Group decision making process for insurance company selection problem with extended VIKOR method under fuzzy environment. Expert Systems with Applications, 39(3), 3702-3707. 